\title{
STUDY ON THE OPINION OF STAKEHOLDERS ON FORESTRY ECOSYSTEM SERVICES
}

\author{
Elena Dragozova $^{1}$, Nevena Shuleva $^{2}$
}

\begin{abstract}
The ecosystem services provided by forest areas have a direct and indirect impact on the quality of life of people and also increase the well-being of society. The regulatory and water protection function of forests is institutionalized in the European and Bulgarian legislation.

In the context of the current crisis in the water sector in Bulgaria there is a need to identify the stakeholder groups involved in the management, protection, control and use of the water ecosystem service. Under the crisis of water management in Bulgaria we understand the reduction of the volume of water resources and difficulties in supplying clean water to the population. Their opinion on the ecosystem of the forest and its water protection function in particular was examined by conducting a survey. The current paper identifies the different stakeholder groups and presents an analysis of the results obtained by means of a questionnaire sent to stakeholders. The results obtained are used as a basis for forming institutional links and managing conflicts in the process of generating, protecting and managing water from its source to the user. The study proved that society makes sense of the connection between the forest and the provision of clean water. Through the study, we succeeded in identifying a major problem related to the incomplete and outdated information on the maintenance of ecosystem services and improvement of the quality of the goods generated from them which is due to the poor communication between institutions coupled with the lack of awareness by the direct responsibilities of various departments and positions. The electronic platform created for the project on the one hand will support the process of information security of the technical mapping of water sources and water protection forests, as well as provide an opportunity for communication with various stakeholders. This will enable a higher information security.
\end{abstract}

JEL Classification Numbers: O13, Q23, Q25, Q26, DOI: https://doi.org/10.12955/peb.v1.15

Keywords: water, forest, ecosystem services, water protection function

\section{Introduction}

Ecosystem water service is vital for human material service that is directly dependent on water protection function of the forest. It has been published by different authors, and they stated that the territory of Bulgaria in mountain watersheds predominant forest vegetation formed $85 \%$ of the water resources of the country, $60 \%$ of irrigated land is irrigated by water coming from forest watersheds and about $60 \%$ of these water resources meet the drinking water needs of the population. (Yovkov; Shuleva, 2011).

The results of the Millennium Ecosystem Assessment project implemented by the United Nations Environment Program in the period from 2001 to 2005 reflect the opportunities for improving human well-being through proper ecosystem management and quality improvement of the ecosystem services. The basis of good management decisions regarding the use of natural resources is the understanding of the main role of the environment, as a basis for increasing social and economic wellbeing (MEA, 2003; MEA, 2005). The 2000 EU Environmental Policy Program (Ecosystem Millennium Assessment, 2005, TEEB, 2010, EASAC, 2009, CBD, 2010) (de Groot, 1992, Daily, 1997, Costanza et al., 1997) set out ecosystem protection as reference points, the sustainable use of ecosystem services, and their connection with the increase of human well-being.

Many authors base the sustainable use and protection of ecosystems on the application of various methods for mapping, assessment, quantitative, including spatial localization for assessment and identification of ecosystems (Burkhard and Maes, 2017). The assessment recommends a multidisciplinary approach that includes combined methods for biophysical, sociocultural and economic impacts. In recent years, scientists from different scientific fields have come together to understand the connection of different EU assessment methods (Dunford et al., 2018, Jacobs et al., 2016). In Bulgaria, after 2010 many research have been conducted and different approaches for assessment of ecosystem functions have been applied. Nedkov et al. (2018) analyze the process of mapping ecosystems in order to meet the priorities set by the EU in this area. That is the basis of our motives for implementing this project assessment of the water ecosystem service provided by forest areas with water protection functions in Bulgaria

Forest protection and the maintenance of the water resource protection function of forests have proven to be the most effective methods for water generation and maintenance of its quality from the source

\footnotetext{
${ }^{1}$ University of Forestry, Sofia, Bulgaria, elena.dragozova@abv.bg

${ }^{2}$ University of Forestry, Sofia, Bulgaria, shuleva.nevena@gmail.com
} 
to the end consumer. Climate change, inefficient management mechanisms and poor communication between institutions in recent years have led to several local water supply crises, severely affecting the quantity and quality of water.

There is a network of links and synergies among different groups of stakeholders within the framework of the overall mechanism for storage, generation, and supply of ecosystem services related to the provision of water. From the socio economic analysis perspective, this will require the input of all stakeholders, the network of links as well as the institutional protection of the right to property

\section{Purpose and objective of the study}

The purpose of this study is to reveal the main preferences for the use of ecosystem services from forest areas and assess the level of awareness so as to identify the factors influencing the choice. On the other hand, it examines the willingness of stakeholders to pay owners to manage the water protection.

The study focuses on investigating the different stakeholder groups that create a network of links and synergies within the framework of the overall mechanism of management and consumption of the water ecosystem service provided by water-protected forest areas. The identification of the different stakeholder groups and their level of awareness is an important part of understanding the economic dimensions of the willingness to pay for the ecosystem service.

\section{Research methodology}

The research methodology of the study involved several consecutive steps presented in Figure 1.

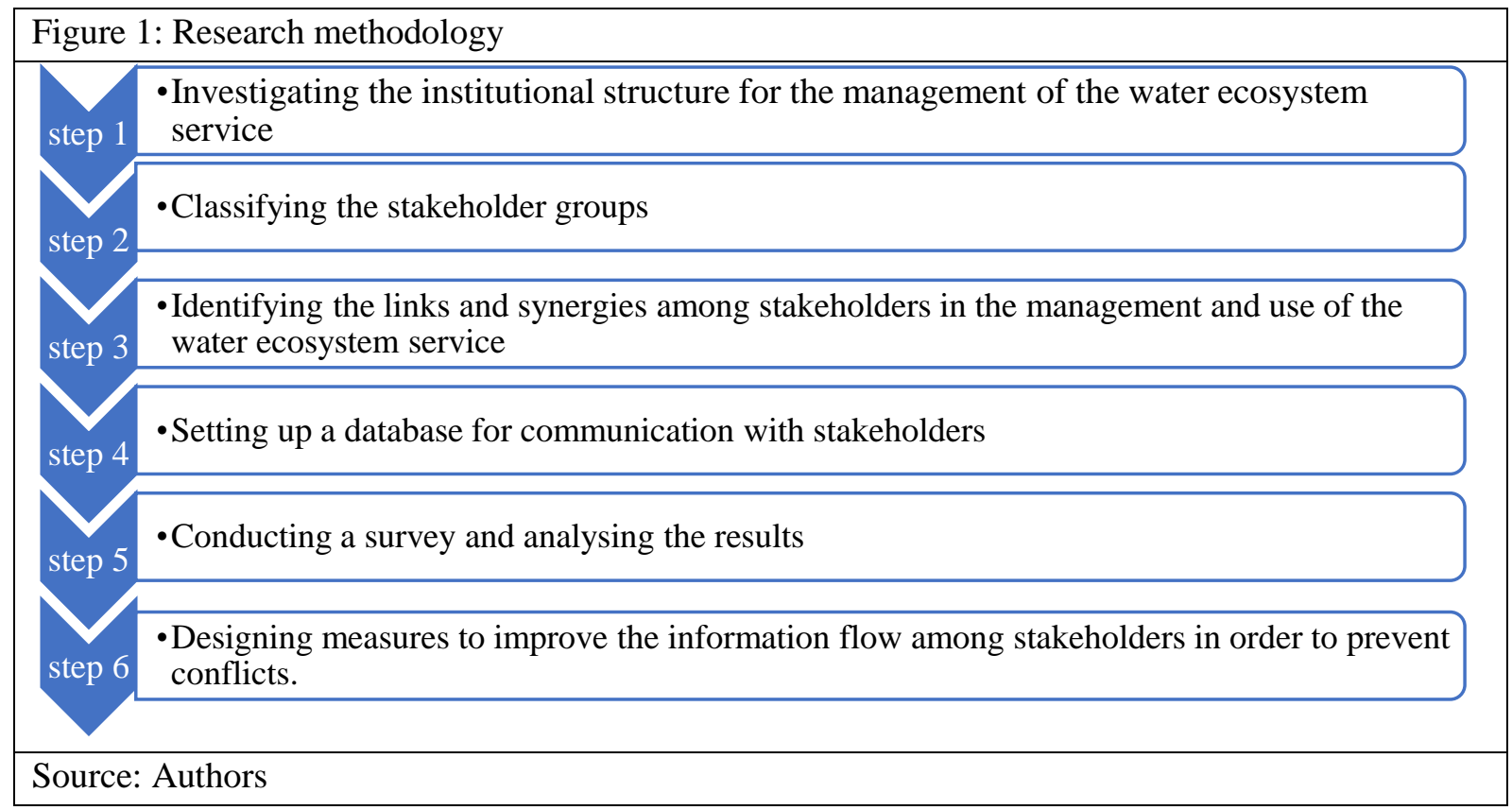

The first stage of the study involved an analysis of the overall process of accumulation, protection, regulation and supply of water to water consumers and water users. During this stage, we identified different stakeholders with economic synergies.. The institutional framework of regulated links and synergies to end consumers of the water service has been presented in relation to this aspect. Figure 2 shows the institutions responsible for water resource management at national and regional level.

The study identified the following main groups classified by shared characteristics:

1. Local and regional authorities and administrative structures (regional and municipal)

2. National, regional and local authorities and structures of the Ministry of Agriculture, Food and Forestry and the Ministry of Environment and Water

3. Associations of local/regional authorities

4. Universities and research institutions

5. Educational and training institutions

6. Business support structures (Chamber of Commerce and Industry, the Economic Chamber, professional organizations, business associations, business clusters, etc.)

7. Protected area administrations 
8. Business structures

9. Civil society structures (NGOs)

10. Individuals etc.

The survey is divided into two parts. The first part contains general questions that provide insight into the respondent's profile, such as sex, age, education, place of residence, and affiliation to any of the above-mentioned stakeholder groups.

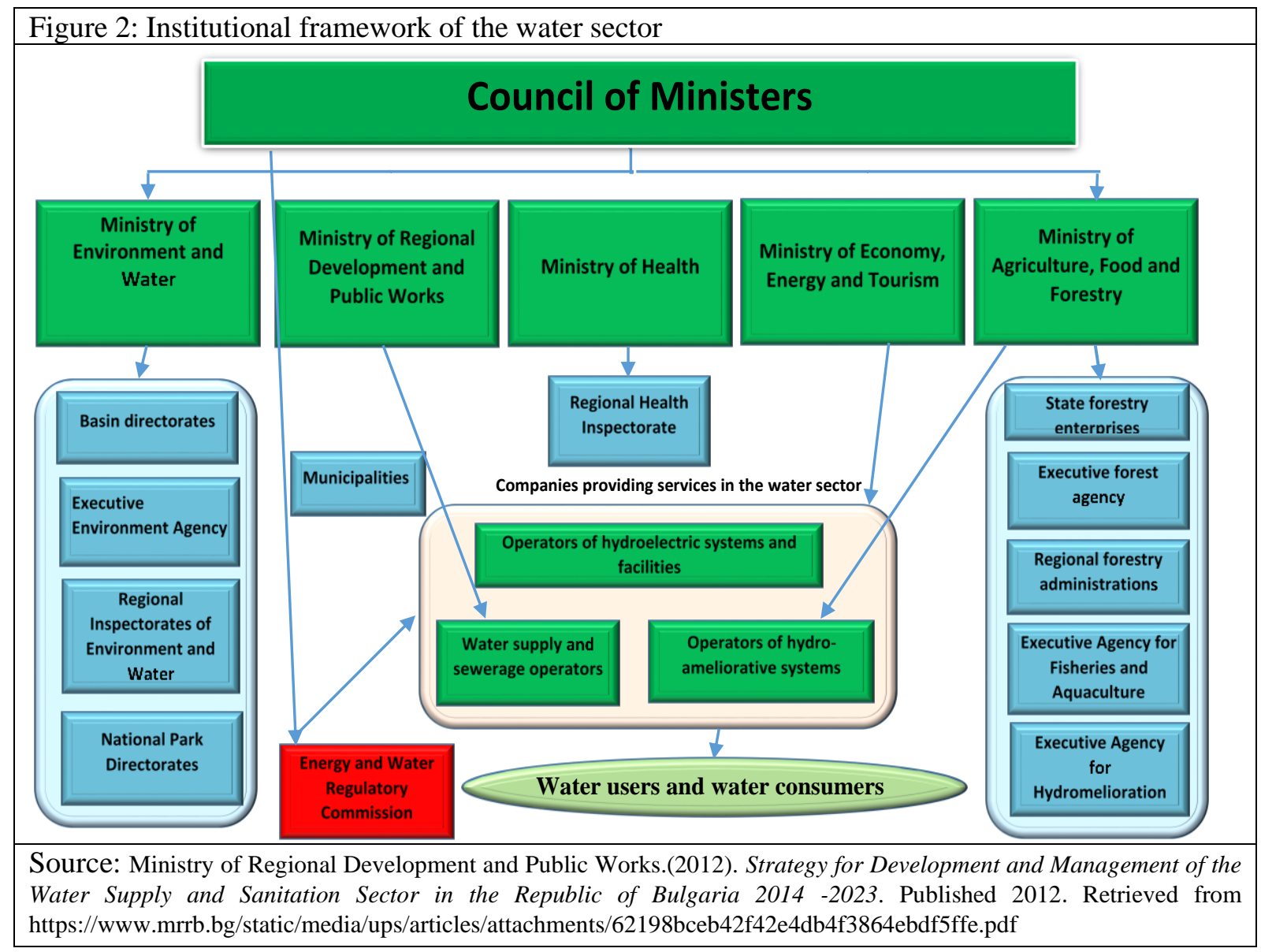

The second group of questions were aimed at determining the extent to which the respondents are aware of the importance of various ecosystem services, how they see their involvement in the process of conservation and management of the resources that provide them. On the other hand, some questions in the survey are aimed at finding out information about the understanding of the process of compensation of the owners of forest areas from which the ecosystem services are provided and how to stimulate the improvement of their quality. The questions also aim to reignite the interest of the stakeholders to obtain transparent information about en the provision of the most vital resource water.

\section{Results and Discussion}

The analysis of the results obtained from the survey produced general data on the respondents such as sex, age and educational background. 70 survey forms were collected and analyzed. The distribution of the respondents by sex is as follows: $52.90 \%$ men and $47.10 \%$ women in different age groups. The distribution of the respondents by age is as follows: 18-30 age group - 10\%, 31-50 age group $25.70 \%$, and $51-70$ age group $-64.30 \%$. The results indicate that there were no respondents over the age of 70 .

The distribution of the respondents by educational background shows that the majority have higher education $-88.60 \%$, followed by those that have a doctoral degree $-8.6 \%$ and those that have secondary education $-1.8 \%$. These data show a high level of interest and social responsibility of stakeholders with higher education.

The distribution of the 70 survey forms which were collected and analyzed as part of the study by stakeholder groups is as follows: local and regional authorities and structures of administration 
(regional and municipal) - 21 survey forms or 30\%; national, regional and local authorities and structures of the Ministry of Agriculture, Food and Forestry, Ministry of Environment and Water - 37 survey forms or 53\%; universities and research institutes -4 survey forms or 6\%; educational and training organizations -2 survey forms or $3 \%$; business support structures -2 survey forms or $3 \%$; non-governmental organizations -3 survey forms or $4 \%$; citizens and others -1 survey form or $1 \%$.

The survey was conducted mainly through electonic means and the feedback was collected after sending the survey to the stakeholder groups. It shows that a higher level of interest and responsibility were demonstrated by those employed in the national, regional and local structures of the Ministry of Agriculture, Food and Forestry and the Mnistry of Environment and Water - $39 \%$ as well as; by representatives of municipal administrations $-21 \%$. This distribution is consistent with job and management responsibilities and competencies of those that participated in the survey.

Given the small number of respondents, the survey does not claim to be representative. The results support the implementation of the next stages of the project "Assessment of the water ecosystem service provided by forest areas with water protection functions in Bulgaria".

The second part of the survey contains questions aimed at determining the awareness -and attitude to the value of various natural resources and the compensation for their management and use.

The first question to the respondents "What is your opinion on the information provided on the topic: 'Sustainable use of natural resources' in your region, as measured by the elements below?" This shows a low to medium level of awareness despite the fact that the respondents are part of structures that are directly involved in the management of the natural resources in question. This shows that the respondents did not receive sufficient and adequate information on the overall use and management of natural resources. The aggregate data expressed in number of responses are presented in Figure 3.

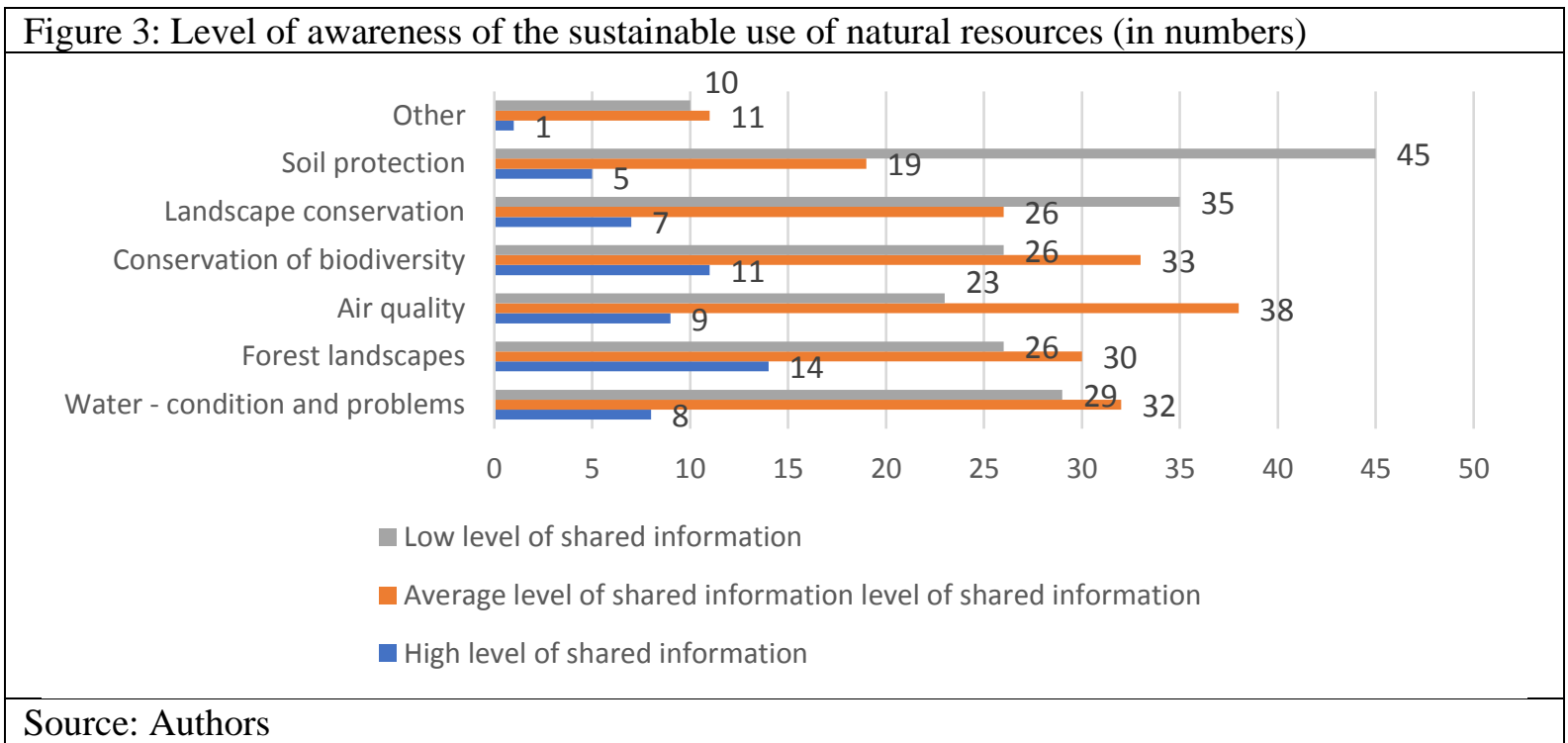

Ranking the goods and services related to forest ecosystems in order of importance, the most important issues identified by respondents are water conservation $-56 \%$ and the use of wood and wood products coming from the forest $-51 \%$. The survey allowed the respondents to give the same ranking to multiple items. The second most important issues identified by respondents are carbon emission reduction, landscape and biodiversity conservation and soil protection.

The answers to the question "In your opinion, which of the following products or services do we pay for?" show that over $66 \%$ of respondents associate tangible forest products with the market, namely timber, wood products and non-wood products. This is tied up with the institutional framework which laid down the valuation and compensation methods for ecosystem services and forest products. For most stakeholders, the ecosystem services provided by forest areas are not visible and their importance is difficult to measure. 


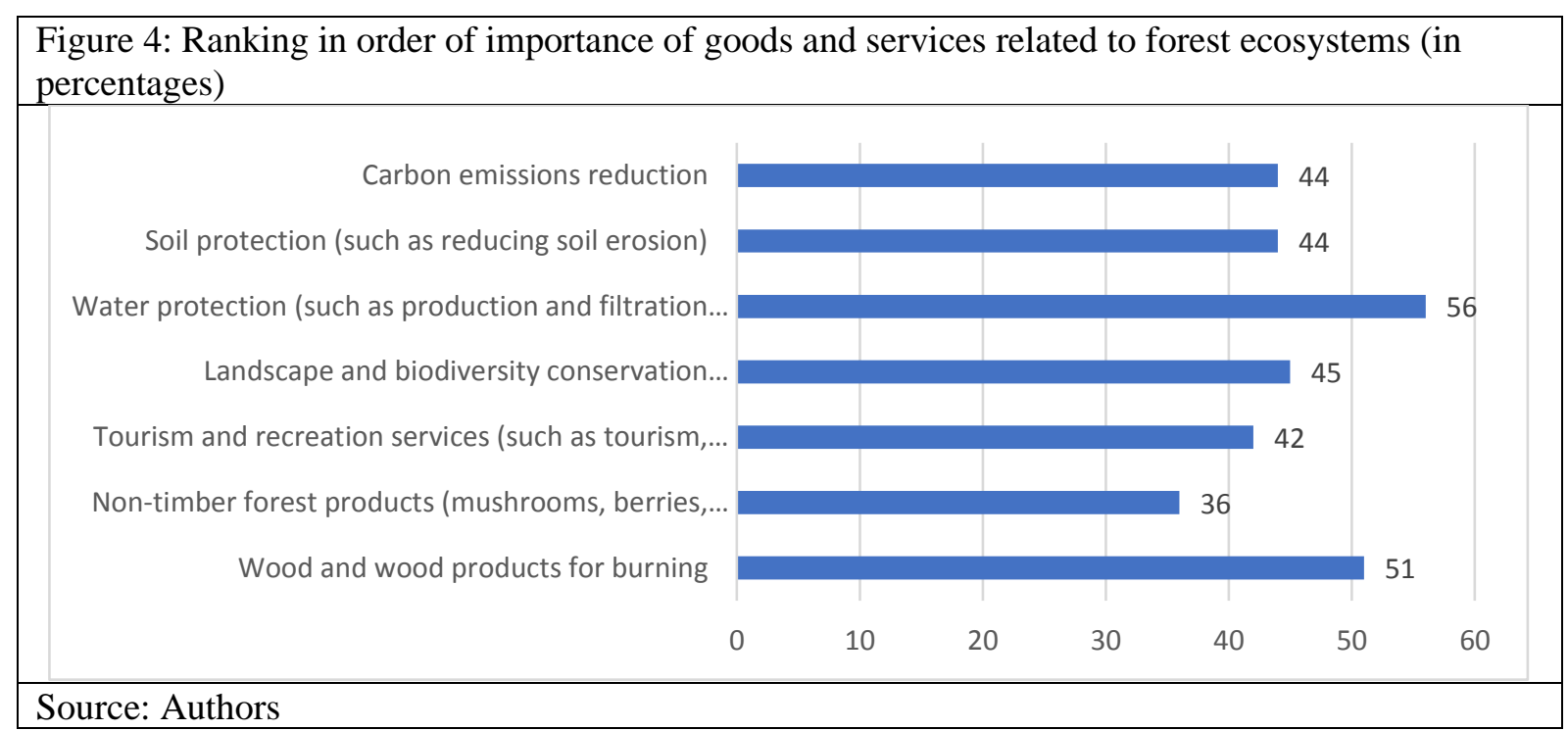

The survey also included the questions: "Which of the following listed public ecosystem benefiting from forest areas would you pay for?"

When the respondents focus on the benefits of the public ecosystem generated in forest areas and link the forest ecosystems to tangible forest products, the results often show a high levels of willingness to pay for most of these services. The willingness to pay to ensure that the quantity and quality of water ranked highest $-55 \%$, followed by conservation of biodiversity $-36 \%$, soil erosion protection $-34 \%$, and regulation of the impacts of climate change. It should be noted that respondents were allowed to choose multiple response options. (Figure 5)

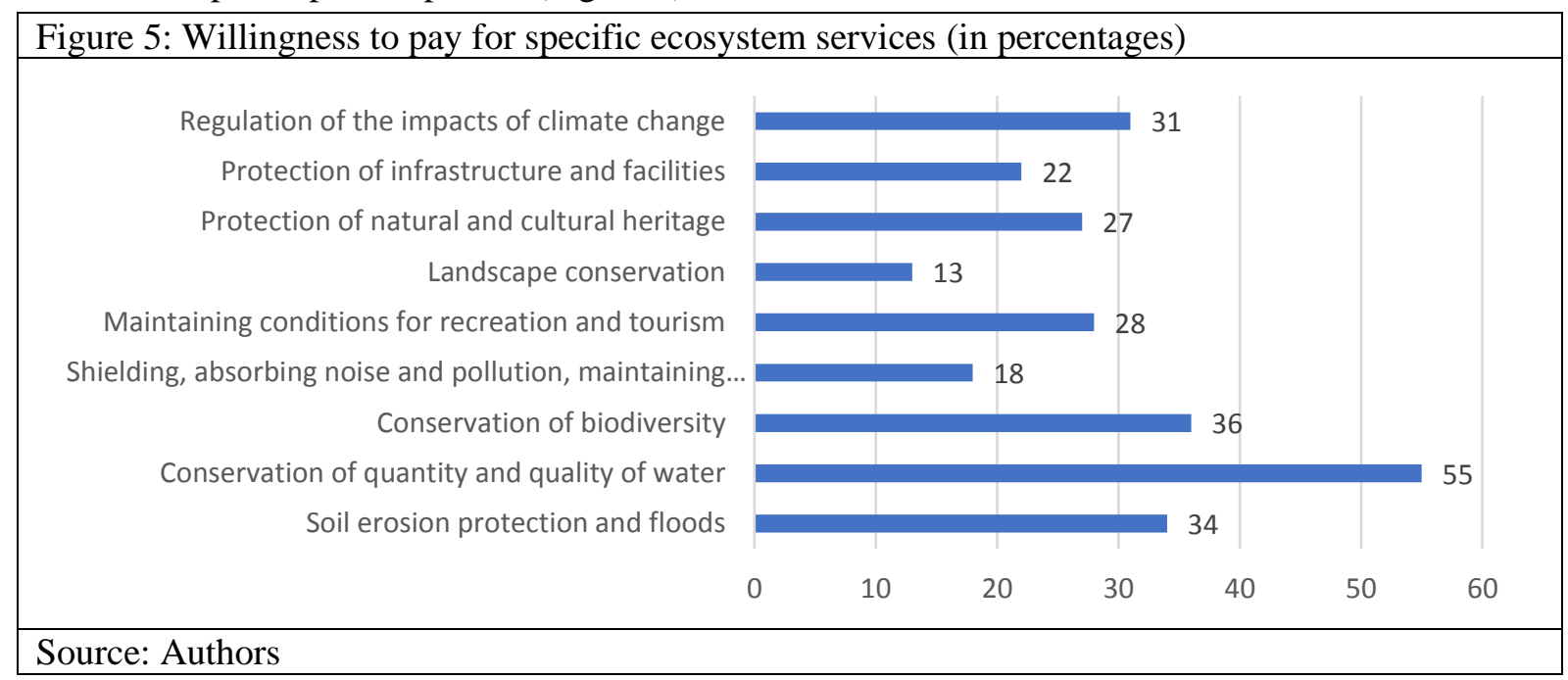

The answers to the question "In your opinion, which of the following public ecosystem goods should be paid to forest owners?" show the same trend for ranking in the conservation of the quantity and quality of water $-47 \%$, conservation of biodiversity $-44 \%$ and soil erosion protection $-40 \%$. (Figure 6)

The results obtained from the responses to the last two questions show the willingness and understanding of the stakeholders about the importance of their involvement in improving the quality of life at present and for future generations. It is important that the respondents realize the need to compensate owners of forest areas so that they can fulfill their private interest in improving their property, and on the other hand ensure that the implementation of socially important measures for the conservation and proper management of ecosystems. Approximately $61 \%$ of the respondents indicated that the management of forest areas in their localities was good, which is a direct positive result from the application of strategically oriented management practices that have brought positive results to several municipalities in Bulgaria. 

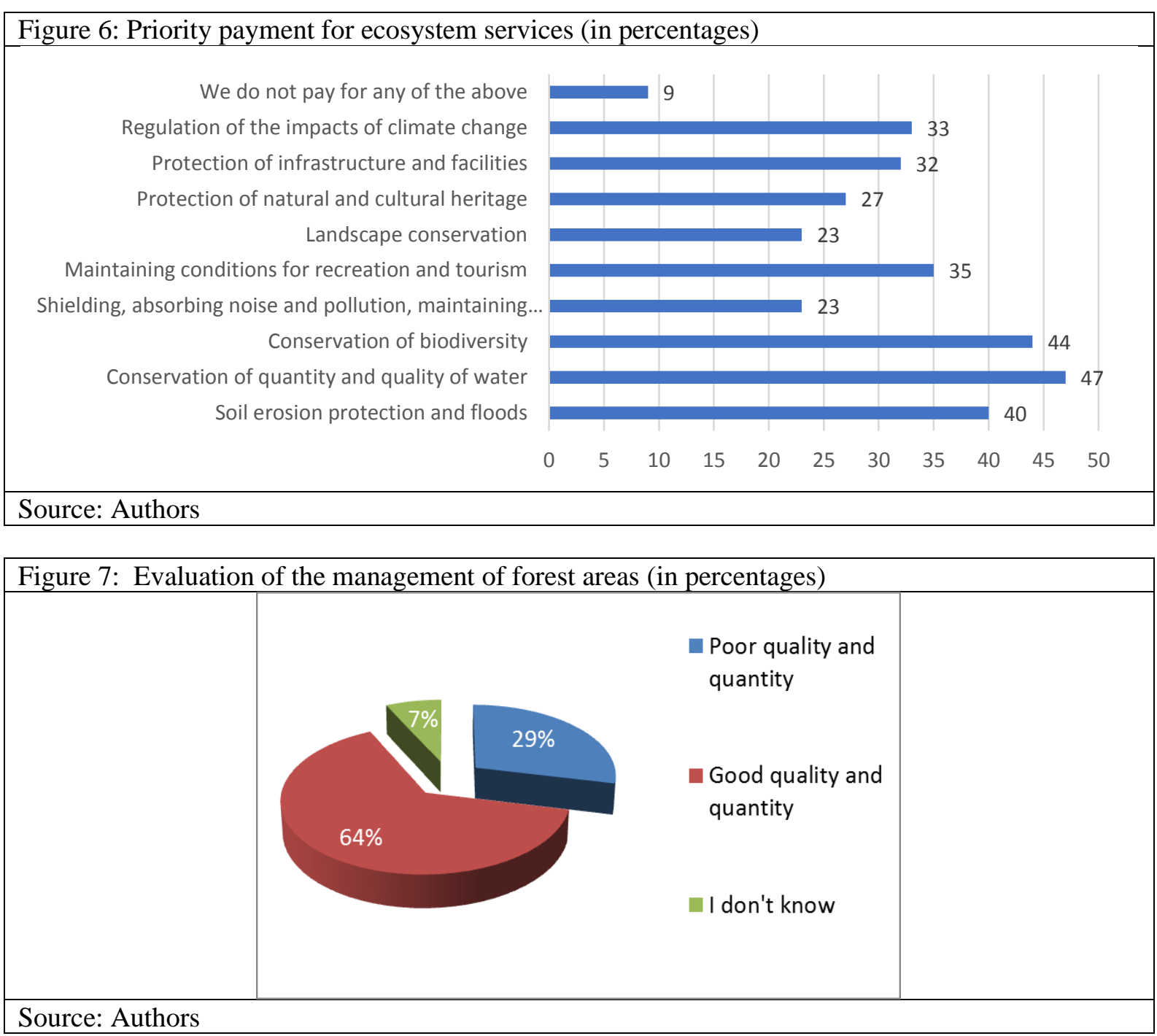

A detailed examination of the responses to the question: "How do you evaluate the water quantity and quality in your municipality?" revealed a direct link between the positive results obtained for good quantity and quality of water (64\%) and the good management of forest areas in the municipalities.

\section{The study identified several key issues that can be summarized:}

1. Incomplete and outdated information on maintaining ecosystem services and improving the quality of the goods they create.

2. Poor communication between institutions and unawareness of the direct responsibilities of various departments and positions.

3. The average consumer gets lost in the network of institutions, relationships and responsibilities. This demotivates his responsible behavior and his participation in the process of management, use and conservation of natural resources on which his well-being depends.

4. No clear for stakeholders legally accepted methodology for valuation of ecosystem services and particularly - costing implement water protection function.

\section{Factors that influence the choice of use and payment for ecosystem services:}

1. Belonging to a social group.

2. Education.

3. Level of information.

4. Trust of the institutions.

5. Transparency of the processes for reimbursement and financing of water management activities.

6. Quality and quantity of local water resources.

7. Economic ability to pay. 


\section{Conclusion}

The study identified a major problem that is associated with the incomplete and outdated information on the maintenance of ecosystem services and improvement of the quality of goods generated from them. This is due to the poor communication between the institutions coupled with the apathetic attitude of the various departments and positions to their direct responsibilities.

The basis of the rational behavior of any economic agent is the extraction of income from the right of ownership or acquisition of the right of use. The institutionalization of the rules and the imposition of obligations on these economic agents can only be effectively and realistically feasible if they receive financial incentives. Providing information and ensuring transparency regarding the mechanisms for management and financing of water management activities as well as the water protection function of forests increases the level of willingness to pay. The survey of stakeholders is an on-going process to provide additional information about the project. In the process of implementation of the set project tasks, it is important to enrich the information resources. In this way, different stakeholder groups can be informed about the condition of water protection forests and their management within a specific settlement.

The decisions made by an individual or a group are bound to affect the value of the ecosystem service, including the water protection function. It is the institutions that protect values and establish a set of rules and norms to ensure the proper functioning of the economy. The main economic principles that the participants in the "game" have to follow are the principle of bounded rationality and the principle of compensation.

The stakeholder database set up during the study and the electronic platform of the project entitled "Assessment of the water ecosystem service provided by forest areas with water protection functions in Bulgaria" enable the improvement of the communication and the active involvement of all parties engaged in the process of water resources management in Bulgaria.

\section{Acknowledgements}

The research leading to these results received funding from the Bulgarian Science Fund - project: "Assessment of the water ecosystem service provided by forest areas with water protection functions in Bulgaria", Contract No. KP-06-OPR 03/7.

\section{References}

BISE. (2019). MAES-related developments in the European Union. Retrieved from https://biodiversity.europa.eu/countries/countries-sections-v3\#\#maes. Accessed on: 2020-1-05.

Burkhard, B., Kandziora, M., Hou, Y., Müller, F. (2014). Ecosystem service potentials, flows and demands-concepts for spatial localisation, indication and quantification. Retrieved from https://doi.org/10.3097/lo.201434

Burkhard, B., \& Maes, J .(2017) Mapping Ecosystem Services. Pensoft Publishers, Sofia, 374 pp. DOI: https://doi.org/10.3897/ab.e12837

CBD.(2010). Convention on Biological Divesity. Retrieved from http://www.cbd.int/cop10/insession/.

Costanza, R., et al. (1997) The value of the world's ecosystem services and natural capital. Nature 387 (6630): 253-260. Retrieved from https://doi.org/10.1038/387253a0

Crossman, N., et al. (2013). A blueprint for mapping and modelling ecosystem services. Ecosystem Services 4: 4-14. Retrieved from https://doi.org/10.1016/j.ecoser.2013.02.001

Daily, G.C. (Ed.) (1997) Nature's Services: Societal Dependence on Natural Ecosystems. Island Press, Washington DC. [ISBN 1-55963-475-8]

de Groot, R.S. (1992). Functions of Nature: Evaluation of Nature in Environmental Planning, Management and Decision Making. Groningen: Wolters Noordhoff. xviii + 315p, illustrated, soft cover. ISBN 90-01-35594-3. Dfl 80. Polar Record 29 (169): 162. Retrieved from https://doi.org/10.1017/s0032247400023779

Dimopoulos, P. et al. (2017). The need for the implementation of an Ecosystem Services assessment in Greece: drafting the national agenda. One Ecosystem 2: e13714. Retrieved from https://doi.org/10.3897/oneeco.2.e13714

Dunford, R., et al. (2018) Integrating methods for ecosystem service assessment: Experiences from real world situations. Ecosystem Services 29: 499-514. Retrieved from https://doi.org/10.1016/j.ecoser.2017.10.014

EASAC (2009) The economics of ecosystems and biodiversity: an interim report. European Communities. Clyvedon Press Ltd, Cardiff.

Egoh, B., Drakou, E., Dunbar, M., Maes, J., Willemen, L. (2012) Indicators for mapping ecosystem services: a review. Publications Office of the European Union, 2012. Retrieved from https://doi.org/10.13140/2.1.3420.2565

Galaz, V., Gars, J., Moberg, F., Nykvist, B., Repinski, C. (2015) Why Ecologists Should Care about Financial Markets. Trends in Ecology \& Evolution 30 (10): 571-580. Retrieved from https://doi.org/10.1016/j.tree.2015.06.015 
Jacobs, S, et al. (2016) A new valuation school: Integrating diverse values of nature in resource and land use decisions. Ecosystem Services 22: 213-220. Retrieved from https://doi.org/10.1016/j.ecoser.2016.11.007

Kolev, K. (2010). Research on economic conflicts in Bulgarian forestry. Forest Science, 3, 65-82. (in Bulgarian)

Liquete, C., Zulian, G., Delgado, I., Stips, A., Maes, J. (2013) Assessment of coastal protection as an ecosystem service in Europe. Ecological Indicators 30: 205-217. Retrieved from https://doi.org/10.1016/j.ecolind.2013.02.013

Mederly, P., et al.(2020) National ecosystem services assessment in Slovakia - meeting old liabilities and introducing new methods. One Ecosystem 5: e53677. Retrieved from https://doi.org/10.3897/oneeco.5.e53677

Millennium Ecosystem Assessment (2005) Ecosystems and Human Well-being: Synthesis. Island Press, Washington DC, 141 pp. [ISBN 1-59726-040-1]

Ministry of Regional Development and Public Works.(2012). Strategy for Development and Management of the Water Supply and Sanitation Sector in the Republic of Bulgaria 2014 -2023. Published 2012. Retrieved from https://www.mrrb.bg/static/media/ups/articles/attachments/62198bceb42f42e4db4f3864ebdf5ffe.pdf

Nedkov, S., et al. (2018) Towards integrated mapping and assessment of ecosystems and their services in Bulgaria: The Central Balkan case study. One Ecosystem 3: e25428. Retrieved from https://doi.org/10.3897/oneeco.3.e25428

Nedkov, S., Zhiyanski, M., Borisova, B., Bratanova-Doncheva, S. (2018) Mapping and assessment of ecosystem condition and ecosystem services across different scales and domains in Europe. One Ecosystem 3. Retrieved from https://doi.org/10.3897/oneeco.3.e29288

Schröter, M., et al. (2016) National Ecosystem Assessments in Europe: A Review. BioScience 66 (10): 813-828. Retrieved from https://doi.org/10.1093/biosci/biw101

TEEB (2010) The economics of the ecosystem and biodiversity: mainstreaming the economics of nature. United Nations Environment Programme, Geneva, 36 pp. [ISBN 978-3-9813410-3-4]

Tsoklinova, M., Delkov, Al. (2019). Factors Inducing on Consumption of Ecosystem Service Tourism, Journal of Balkan Ecology, Volume 22, No 3.

Yovkov, I., Shuleva, N. (2011), Water production function in forest management models, S., 195 ISBN: 978-954-323-827-9. 